\title{
Education policy: explaining, framing and forming
}

\author{
Dr Paul Adams \\ Senior Lecturer, Curriculum and Pedagogy Policy \\ Room LH504 \\ Lord Hope Building \\ School of Education \\ Faculty of Humanities and Social Sciences \\ University of Strathclyde \\ 141 St James Road \\ Glasgow \\ G4 OLT \\ Tel: +44 (0) 1414448078 \\ Email:paul.adams@strath.ac.uk
}

\begin{abstract}
This paper presents a new heuristic device for the analysis of educational policy. Through an examination of the Evaluative State and the work of Brian Fay, the paper considers the way in which educational policy is subject to rational and linear forms of policy action and implementation. To counter this, positioning theory is deployed to consider the way in which we are produced both by discourse and the language of the 'moment' in discursive acts. Using the work of Gee, the paper contends that policy texts and policy Discourse 'themselves form policy, that is, they position policy explanation and policy framing within the bounds of the institution and so give policy form.' Problematically, such mechanisms may succumb to the 'death of subject' and accordingly I offer a third method by which we might conceive of education policy: the discursively produced position call. Subsequently, I propose a tri-partite theory for the examination and understanding of policy: policy explaining, the production of policy texts; policy framing, the ways in which all can be positioned by texts and Discourse to produce the meanings imbued upon policy; and, policy forming, the impact of moment-by-moment conversational acts for their production of the
\end{abstract}


policy text itself, that is, the ways in which policy is locally formed rather than locally mediated.

\section{Introduction}

This paper signals a way by which one might examine policy and its effects. It takes as its theoretical base positioning theory. The paper starts with the work of Brian Fay (1975) to point out the mechanisms by which current educational policy construes educational advancement in simplistic and politically driven ways. Here I show how the advancement of the 'policy engineer' (Fay, 1975) positions education in ways inimical to an understanding of wider conceptions of what it means to engage with and form policy. The ways in which current education is positioned as policy science thinking is outlined. Following this I discuss positioning theory; that is how Discourse offers position calls by which one might come to understand work in the educational domain. Problematically, though, such mechanisms may succumb to the 'death of subject' and accordingly I offer another method by which we might conceive of education policy: the discursively produced position call. Coming out of positioning theory, the position call is a way of understanding the interplay between macro Discourse (Gee, 2012) and the micro level of the discursive act. I follow this with a tripartite way of conceiving of policy and related policy analysis mechanisms. Specifically, I propose that we understand and work with policy in three realms: policy-explaining, the production of policy texts; policy-framing, the ways in which all can be positioned by texts and discourse to produce the meanings imbued upon policy; and, policy-forming, the impact of moment-by-moment conversational acts for their production of the policy text itself, that is, the ways in which policy is locally formed rather than locally mediated. In this way, I contend that discursive moments themselves form the very policy they seek to understand, that is, they position policy-explanation and policy-framing within the bounds of the institution and so give policy form. This heuristic device overlays positioning theory as a mechanism whereby the researcher might investigate the specific ways in which individuals and groups articulate positions for themselves in light of policy text, policy discourse and the very local, conversational acts undertaken in an attempt to form wider policy 'moments'. 


\section{Policy Science and the Evaluative State}

Since the 1980s, western education has been subject to major reforms. Throughout this time, successive governments have sought to reduce what they claim is waste and ineffectiveness so as to increase efficiency and realign the public sector with private sector ideals and mechanisms. Market principles have found their way into the very heart of education as government interventions adopt the mantras of efficiency, performance and standards. It is not just that business provided a rationale for the outcomes of schooling; skilling for the economy is not the only way in which education is oriented. Rather, the values and ethos of business provide an ethical base for operationalising education and for defining how success might be judged.

However, such positions present something of a problem: to require excellence as an outcome necessitates mechanisms by which success can be judged. It is here the rise of the Evaluative State (Neave, 1998) readily presents itself, replete as it is with messages concerning the relationship between decontextualised positivist measures and success of the educational system as a whole. Wrapped up here are certain principles which, taken together, provide for this new line of thinking (Dill, 1998: 361):

- output as specified by performance objectives centrally identified and articulated;

- authority over inputs and decisions about resource use increasingly delegated to agencies;

- the use of competition and privatisation as a means to encourage performance accountability.

What is notable are the uses to which language is put and the means by which such language is expected to become part-and parcel of educational practice and parlance: the use of the term 'performance' has become almost a mantra. Pupil performance is judged against national tests, teacher performance against performance management mechanisms, and schools themselves are judged by schools' inspectorates and often through league tables of exam results. Under the principles of the Evaluative State, educational performance is specified, not in terms of sociological matters such as a contribution to reducing poverty, but in terms of simple output measures judged against government objectives. Accountability is the buzzword. 
Whilst the substance of policy may change from locality to locality, in recent years, the use of statistical methods for determining performance remains. The rise of the Organisation for Economic Co-operation and Development's (OECD) PISA ranking is a case in point. The assumption is one of causality. What was, and remains, at the heart of government policy is the belief that simplistic outcomes might tell us the best course of action to achieve efficiency.

\section{The rise of the policy engineer}

In such situations and in much writing on the subject, policy is taken for granted or only dealt with superficially (Ball et al, 2012); policy is often described as a thing that individuals can come to know, identify with and implement. Associated simplistic linear models are applied whereby policy is seen to be designed, implemented and evaluated in a causal manner. This is reminiscent of the work of Brian Fay (1975) who coined the term 'policy science', describing it as '...that set of procedures which enables one to determine the technically best course of action to adopt in order to complement a decision or achieve a goal' (Fay, 1975: 14). Policy science subjects social phenomenon to close analysis through the auspices of a natural science mode of enquiry, the concern being the formulation of a '...rational and scientific prescription for action and future policy' (Grace 1995: 2-3). Accordingly, it is the job of the policy engineer to '...choose the most efficient course of action in terms of the available scientific information' (Fay, 1975: 14) and so solve political problems.

This is relevant when considering the relationship between the Evaluative State and education. The use of a hypothetical-deductive model to judge performance coupled with causal explanations for the relationship between identified and monitored inputs and outputs ('better' teaching engenders 'better' results) positions education. Hence the contexts for the Evaluative State become the guiding principles for judgement. Education policy is akin to a policy science in that it is '...reactive and infatuated with the description and evaluation of organizational reform, management improvement and implementation strategies and procedures' (Troyna, 1994: 4). A preoccupation with 'what works' articulates a set of strategies geared towards the improvement of educational practice (Avis, 2006) distinctly oriented towards simplistic and dispassionate output measures: more pupils 
achieving a set standard; fewer 'satisfactory' or 'unsatisfactory' schools; more teachers observed and graded as 'good' or better; and so on.

Whilst 'better schools', 'better teachers', 'better discipline', for example, become elements of political positioning, the adoption of policy science methods reinforces the place for the judgement of educational evaluation and efficiency. The policy science approach is held up as the only truly objective means by which the relations within systems can be studied. It is a 'science' and it offers observable, reproducible, rigorous, uniformly applicable and publically verifiable means. Causality gives predictability; desired outcomes can be planned for and achieved, unwanted events prevented.

This orientation seeks to desensitise evaluation mechanisms to emotional debate and political disagreement. If a policy science approach is able to tell us the best course of action to a particular end and such an end is 'identified' as the most 'efficient' and 'best', then general acceptance of this end proscribes political disagreement. As the best course of action has been 'objectively' shown to be the best course of action, political discussion will cease. But, as Fay notes, policy science tells us no more than 'what is the case'. The policy engineer does not decide the direction for policy; rather s/he details the most efficient means to the achievement of desired ends based on arguments of accrued benefit and goals, set against courses of action technically arrived at through the utilisation of explanatory-causal accounts. So is seen that policy is not created, but implemented and recycled. Methods judged previously as worthy in their educational adeptness become reused, extolled once more as paragons of virtue. For example, in England, a return to whole class teaching, synthetic phonics and more time in the classroom whilst training follow (DfE, 2010), replete, as they are, with the power of history.

This is a technology of performance, a techne of government and of enactment, which gets policy 'done' in very effective ways by creating an economy of visibility which brings students, teachers and schools directly into the gaze of policy... (Ball et al., 2012: 139 emphasis in original)

And so it is that we have seen the rise of one form of the policy engineer, the political advisor. We see a rise in an active and centralised government seeking to engineer 
institutions in line with political imperatives derived from scientific canons (Fay, 1975: 27). Politics, and by implication educational thought, thus becomes synonymous with administration and hence a technical activity demanding instrumentalist solutions.

Here policy is both de-politicized and thoroughly technicised; the purview of the policy scientist is limited to and by the agenda of social and political problems defined elsewhere and by solutions already embedded in scientific practice... (Ball, 2006: 56)

Such arguments suggest, then, that the policy science approach has gained considerable ground as the means whereby education can be seen to be effectively construed and audited.

What this entails is the use of particular behavioural characteristics divorced from wider sociological and historical considerations in an attempt to offer an objective account of 'what is' and 'what should be'. Such technical endeavours offer succour to policy-makers in that simplistic cause and effect matters can be identified and implemented. Problematically, embedded social, cultural, historical and value positions become lost in analysis and thus deeply engrained matters bound up with issues at hand are never resolved. Essentially, policy science desensitises the policy-making processes to the rigours of everyday life.

...what gets lost in this perspective is the examination of the politics and ideologies and interest groups of policy making-process; the making visible of internal contradictions within policy formulations, and the wider structuring and constraining effects of the social and economic relations within which policy making is taking place. (Grace, 1991: 26)

The policy science approach usually rests on a deliberation of efficiency. As Fay writes though, as a measure this is relational: to compare the rate of work in one area against, for example expenditure, requires a comparator standard, a 'unit of measurement'. However, the identification of such measures is surely a value decision: to decide upon what to base the comparison necessitates deliberation as to what is worth comparing it too, i.e. what is important in rating efficiency. For example, the use of international test scores such as PISA as a means by which to identify high performance is predicated on the decision that tests of the form currently employed are a measure of learning (something with which schools are 
necessarily concerned) and a decision that what is valued by those for whom the tests are instigated (parents, government) is information in this form. Social activities are, though, ethical endeavours; they require consideration of the effects of action. Thus, in the preceding example, we see that the adoption of test scores as the basis for deliberation of the effectiveness and efficiency of a school is an ethical act: underpinning such choices are assumptions about the effects and affects on individuals and groups and how these are justifiable or not.

As Fay notes, attempts to decontextualise and objectify success often occur in an effort to 'improve', particularly, public services; education is no exception. As seen above, the rise of the evaluative/market state is an attempt both to instil the principles of the marketplace into education and hold up for scrutiny efficiency, improvement and accountability. That such measures are notably positivist in orientation and operate from a conception of public and social life replete with the objectification of 'progress' illuminates the hegemony the policy science approach enjoys in political decision-making. And for Fay:

...the idea of a policy science is one of the deep, important, and enduring ideologies of our own time, one which is all the stronger in that it claims to be 'objective' and 'scientific'. (1975: 64)

And it is not that this situation is necessarily unreflective: situational 'truth' has been identified along with personally held visions about change and social order, and a means by which these visions might be realised has been chosen. But here we see the technicality of teaching, the technicisation of education. It is how 'best practice' becomes reified. Consider, then, the recent overtures towards times tables and long division cited by the Coalition Government as measures of educational success.

\section{An alternative to policy as 'thing'}

But such views do not prevail in the academic literature however. Indeed, for many the idea that policy can be objectified runs counter to the lived experiences of those working in policy rich contexts. For the last 20 or so years, policy theory has moved on from that which Fay decried towards more nuanced and subjective interpretations. There has been recognition that seeing policy in such reductive terms means that all matters not closely 
bound up with the immediacy of the policy statement become lost, marginalised or go unrecognised. Accordingly, policy has come to mean much more than this and is viewed as both 'texts and 'things' and discursive processes that are complexly configured, contextually mediated and institutionally rendered.' (Ball et al., 2012: 3); the policy process is one of interpretations of interpretations. In this way, then, policy can be seen as a becoming: a process of realisation and formation imbued with human endeavour and desire.

Policies 'begin' at different points and they have different trajectories and life spans, some are mandated, others strongly recommended or suggested (Wallace, 1991). Some policies are formulated 'above' and others are produced in schools or by local authorities, or just simply become 'fashionable' approaches in practice with no clear beginning. (Ball et al., 2012: 7)

Here, then, there is a need to understand the ways and means by which policy is both formed by everyday professional action and positioned by wider social and political forces. Ball (2006) offers an excellent mechanism by which this might be considered through his discussion of policy as text and policy as discourse. Similarly, Ball et al. (2012) note the ways and means by which policy enactment rather than implementation gives rise to different types of policy actor, policy subjects and policy work.

As teachers engage with policy and bring their creativity to bear on its enactment, they are also captured by it. They change it, in some ways, and its changes them. The degree of 'play' involved in this interface varies between policies. (Ball et al., 2012: 48)

Theirs is a proposal for the translation and transaction of policy forms; an understanding of the diffuse nature of policy enactment. Whilst its tenor is, I contend, accurate, there is the need for a mechanism by which we might comprehend the substance of policy and realise its positioning in both discourse and Discourse (Gee, 2012). There is a need to consider a mechanism by which one might uncover and examine the diffuse nature of policy formation; for I contend that enactment is, in effect, the formation and reformation of policy at a number of levels. In this way I am seeking a means to both understand and provide opportunities for change; specifically, I am concerned with identifying ways in which professionals might structure and form policy in relation to: the production of forms of representation that attempt to convey, unambiguously, meaning and intent; the forces that 
seek to position the 'reader' and 'enactor' of policy; and, the local, discursive acts that form and reform policy: the discursive moment. I wish to undertake this through the prism of positioning theory, a theoretical lens that I believe offers much in the drive to understand the mechanisms by which policy is formed and reformed.

\section{Positioning policy}

In the literature there is little agreement as to what constitutes discourse; with many writers the origins of the term they use are never expounded and in this way the reader is often required to read between the lines. Some, such as Ball (cf. 2006) do make their position clear: his is a position which utilises the work of Foucault (cf. 1972). For others, however, origin \s are more illusive. Gee was himself influenced by Foucault's writing and in this way shares some similarity. However, Gee's work stems from a Critical Discourse perspective whereby discourse is seen to stem from elites and non-elites as well as oral and written forms (Strauss, 2012). Indeed, it was Gee's frustration with '...discussions of power that were always about oppression, imperialism, and post-colonialism, and postmodernism' implied by Foucault's writing that led him to Critical Discourse methods and theories (Rogers, 2004: 8).

For Gee little-d/discourse consists of '...stretches of language which "hang together" so as to make sense to some community of people, such as a contribution to a conversation or a story' (112). Such terms define the discursive act, the means by which we engage in conversational moments. In this way it is possible to conceive of the ways and means by which sense-making can be uncovered through moment-by-moment discursive events.

What such matters highlight, though, is the need for one to understand the ways in which language is embedded in society and social institutions (Gee, 2012: 112) and so, in contrast,

A Discourse with a capital " $D$ " is composed of distinctive ways of speaking/listening and often, too, writing/reading coupled with distinctive ways of acting, interacting, valuing, feeling, dressing, thinking, believing with other people and with various objects, tools, and technologies, so as to enact specific socially recognizable identities engaged in specific socially recognizable activities. (Gee, 2012: 152) 
Big-D/Discourses are ways of recognising and getting recognised. However, Discourses can be recognised in multiple ways; thus Discourses are about enactment and recognition. They are about socially accepted association in language and other expressions of thinking, feeling, etc.; the various ways we use tools, technologies and props so that we might identify ourselves as a member of a socially meaningful group to signal that we are filling a social niche in a recognisable fashion (Gee, 2012: 158). Discourses are mastered by enculturation into social practices through scaffolded interaction with others (Gee, 2012: 167-168). Thus, behaviour becomes meaningful only against the Discourse, or a set of complementary or competing Discourses that "can "recognise" and give meaning and value to that behaviour.' (Gee, 2012: 190). What someone says is a product of the Discourses they are in at the time and the other Discourses of which they are a member.

\section{Positioning Theory and the process of realisation}

The theory of positioning as a means by which one might understand and consider the dayto-day perspectives of everyday discourse and language has been noted in the literature for some time. From its origins in narrative psychology, it has broadened its scope and appeal (Burr, 2003). More specifically, writers such as Harré (2004), Harré and van Langenhove (1999) and Drewery (2005) have extended the idea to explore more specifically the ways and means by which interaction through language creates us as subjects. Specifically, it seems to have found a welcome niche as a conceptual tool by which researchers might uncover and explore how '....we come to take up certain identities and not others' (Drewery, 2005: 306). As it is a relatively new phenomena by which methodology might be considered, it has no, one, single definition. But this should not detract from its importance, especially if a particular way of conceiving of positioning theory can be garnered for the purposes of educational policy analysis.

Starting from the premise that positioning is 'the discursive process whereby selves are located in conversations as observably and subjectivity coherent participants in jointly produced storylines' (Davies and Harré, 1999: 37) some (e.g. Willig, 2000) argue that it is useful as a means by which snapshots of experience and perspectives might be understood. Others, particularly Drewery, argue for a more dynamic interpretation and use of the theory 
to explain how subjective experience is produced, thereby providing opportunities for critical reflection and analysis of preferred forms of subjectivity through the formation of differing types of 'positions calls', that is, implicit invitations to take up subject positions. Indeed, when writing about counsellors and counsellor educators, Drewery highlights the need for the development of '....sensitivity to the constitutive effects of conversations' (2005: 306) and in so doing helps us think about '...the productive impacts of colonizing language' (2005: 307). Her call concerns the interpersonal; the area of consideration is that of the conversation, the immediacy of the moment of discursive production. In a wider context, van Langenhove and Harré (1999: 103) note that,

Positions usually involve not only speaking and writing rights, duties and obligations, but also expectations as to how someone in a certain position will exercise their rights...

It is this broadening of the frame for positioning that raises interest here; this notion that through a variety of discursive acts (conversational moments), positions can be offered and amended, taken up or resisted. The assumption here is that human behaviour is goaldirected, constrained by group norms and that human subjectivity is the product of a history of human interaction: during conversations, storylines are used to make words and actions meaningful (Barnes, 2004). Here, storyline is

\footnotetext{
the narrative which is being acted out in the metaphorical drama. Within it, the positions are the parts being performed, possibly only fleetingly, by the participants. The actions (including utterances) of the participants are given meaning by the storyline and the positioning of those involved, and once given meaning become acts.' (Barnes, 2004: 1-2)
}

It is thus easy to see that positions are not fixed but fluid. They change from moment to moment depending on the interpretations and sense making of the agents therein. This constant flux seems in contrast to the observation that people often behave consistently. Positioning theory maintains that our 'selves' are made in discursive moments and not through our biological makeup. The social act sets out to solve social problems not merely describe them (Jones, 1999). As Harré (1997: 182) notes, 
'The meanings of a person's actions are the acts they are used to perform. But those acts come into being only in so far as they are taken as such by conversational partners ... I don't and indeed can't decide what my actions mean. Only you and I can do that. The investigation of the devices by which some people can manage to get you to give my meaning to what both of us say and do is the study of power.

Now, this is not to deny that our 'selves' take meaning from actions; rather it notes that for such meaning to occur they have to make sense in terms of social referents. In this instance the person is not 'subjected' to pre-existing Discourses, but, rather, subjectively constructs the Discourses for themselves. In this way the person becomes someone who is accountable for his or her own actions (Bamberg, 2004); there is an agent-to-world fit (Korobov and Bamberg, 2004) brought into life through language existing only as concrete occasions of language in use (Linehan and McCarthy, 2000). The theory posits that within the person/conversation reference, positioning is a process whereby speakers construct personal stories within discourse, and such stories are taken up or resisted. In this way actions are made intelligible and determinate as social acts (Tan and Moghaddam, 1995).

It is, then, possible to identify the positioning triangle (figure 1); a model to explain the interaction between the positions people are offered and those they might hold, the storylines that abound and the social force of the language used to bring about effect (Van Langenhove and Harré, 1999). This triangle highlights the discursive construction of personal stories that make actions intelligible.

\section{Take figure 1 here}

Such views stem from a micro social constructivist Discourse. Indeed, positioning theory has been criticised for ignoring the macro (Ofreneo and Montiel, 2010). But there is another view of positioning theory which stems from this latter perspective. One can argue, from the preceding, that local moral orders confer rights duties and obligations on the participants in a discursive event. Now, such orders may well exist as a manifestation of the very conversational act but it is also the case that wider Discourses abound in such instances and, in turn, offer positions of their own (Bamberg, 2004). In this regard Discourses constitute 
the individual position from a number of on offer. As Holloway notes 'Discourses make available positions for subjects to take up. These positions are in relation to other people' (1984: 233). In this perspective, speakers become 'the person' who is 'already positioned' in a top-down fashion (Bamberg, 2004). Discourses provide the 'meaning' within which positions are taken. As Discourse is seen as inherently in conflict, individuals are said to have to choose. Positions are, therefore, resources from which subjects can select; being positioned has a world-to-agent fit (Korobov and Bamberg, 2004).

'Written' forms carry weight here. Indeed, these, as part of the social world, can be said to be both producers of position and reflectors of position, producers of Discourse and reflectors of Discourse: processes of positioning are constitutive of what befalls the written in the public and social domain and reflects the ways and means by which positions are offered. Similarly, the written form itself reflects a discursive process set within wider social and political domains. As Ball (2006: 45) notes

The texts are the product of compromises at various stages (at points of initial influence, in the micropolitics of legislative formation, in the parliamentary process and in the politics and micropolitics of interest group articulation).

Here, then, we should consider not only wider Discourses but also texts themselves including the conditions prior to production, the process of writing and the constitutive effects of text in further positioning processes for all provide position calls in their own right.

Clearly, though, texts are the product of political actions played out in the socio-cultural realm. Here, then, we can consider the policy text: the written forms of policy mandate expressed in a variety of forms and delivered via a variety of media to the various agents involved in the process; educational policy is no exception. But we should ask further questions as to the place of these texts in the policy formation-action-reflection cycle; we need to be clear as to how they provide for position calls. Indeed, we need to reflect on what we mean by position calls in such a situation. We need to consider not only the 
production and distribution of these textual forms, but also the interrelationship they have with wider Discourse and actions taken at the local level of the institution.

Stephen Balls' work on this is clear: to understand policy we need to consider it as both text and as Discourse. As he states

...in the analysis of complex social issues - like policy - two theories are probably better than one, or to put it another way, the complexity and scope of policy analysis - from an interest in the workings of the state to a concern with contexts of practice and the distributional outcomes of policy precludes the possibility of successful single theory explanations. (Ball, 2006: 43)

What I am arguing for here is an overlaying of positioning theory as a mechanism by which we might uncover the relative determinant acts which seek to form policy. Whilst I have outlined micro and macro positioning theory I here contend that there is a need to consider them together. As Bamberg (2004) states, it is possible to reconcile the two views of the subject. Willig (2000) notes that the macro view traditionally ignores the ways in which Discourses are taken up, negotiated or transformed in conversation and action, but as he states

'A move towards a 'phenomenology of everyday life and subjectivity' (Lupton, 1997: 104), therefore, allows us to study individuals' resistance to dominant discourses, and the emergence of alternative subject positions as well as subversive practices.' (Willig, 2000: 554)

On the one hand, then, there is a need to consider Discourse for through this is given the meanings and norms that guide human thought and action. As Holland et al (2008: 155) note,

individuals have different senses of self because, senses of self being grounded in experiences of power, individuals have differential access to the positions of power that afford the experience. People develop different relational identities in different figured worlds because they are afforded different positions in those worlds. 
Alternatively there is a need to understand how language is used to realise social tasks for the meanings of words are the social tasks they accomplish (Slocum-Bradley, 2009). In order to understand human behaviour and thus understand policy, the analyst must understand how people use Discourse to construct meaning in specific contexts (Slocum-Bradley, 2009). Such 'discursive positioning' (Winslade, 2006) points to the ways in which individuals, within conversations take up positions in relation to Discourse through conversational acts: people position themselves are positioned in relation to on-going and past conversations. The language used offers position calls in both obvious and subtle ways. Acknowledging that individuals can accept or refuse position calls highlights the non-deterministic nature of our discursive worlds; in this way we exercise agency. Agency is discussed later in this paper; suffice to say here:

\footnotetext{
I am referring to the ways in which any utterance in a social interaction ... calls on a discursive background in order to make sense. As it does so, perhaps, outside of the conscious intention of the person making the utterance, it is inserted into a social context made up of patterns of meaning, often in contest with other meanings ... They can even obscure the possibility that other meanings exist. (Winslade, 2006: 505)
}

Using 'position' instead of role or type shifts discussion from the ritualistic and formal to the dynamic and negotiable; identity should thus be seen as actively negotiated and achieved rather than fixed and given (Tan and Moghaddam, 1995). This describes a social world ordered through construction; of note here is the socio-political: the micro-politics of discursive acts and formational activities.

\footnotetext{
By attending to features of the local context, in particular normative constraints and opportunities for action within an unfolding story-line, it becomes clear that access to and availability of certain practices, both conversational and practical, are determined not by individual levels of competence alone, but by having rights and duties in relation to items in the local corpus of sayings and doings. (Harré et al, 2009: 6)
}

\section{Policy analysis}

There are three points to consider here. First, the social, cultural and political milieu preceding the formation of text is of note and must surely be of concern. Such wider frames 
both pre-date and come out of policy. Second, the texts themselves do not constitute policy; rather they are physical explanations of events and discussions, discourse and debate. Third, the discursive processes involved in attempts to understand policy texts at the professional level form policy, that is, they position policy explanation and policyframing within the bounds of the institution and so give policy form (Adams, 2011).

With this in mind I propose the conception of a tripartite approach to examining policy through the lens of positioning theory:

- Policy explanation: the interrogation of texts to give rise to possibility and option;

- Policy-framing: the location of wider frames for the possibilities for action; a consideration of Discourse as the provider of position calls;

- Policy-forming: the ways in which positions are taken up or resisted at the local level in an attempt to 'understand' policy-explaining and discourse; this itself forms policy.

\section{Policy-explaining}

Policy pronouncement takes the form of texts. What I mean by this is the production of forms of representation that attempt to convey, unambiguously, meaning and intent. These take many forms in contemporary society, such as media-blogs, web-based documents, physical texts and video-entries. Of note here is the fact that behind the veneer of accessibility lies a series of discussions and debates as to what is correct and what is seen to be correct; interpretations matter. Policy texts have a history, both interpretational and representational; they are the product of debate, discussion, interpretation and reinterpretation (Ball, 2006). They are manifest by different actors in the policy text-making process. They are read and digested by a multitude of individuals and groups and meaning is taken differently. But the need to interrogate these texts remains, not in an attempt to uncover the 'truth' but to give rise to possibility and option. Policy research needs to consider the textual form as one location for analysis; one arena in which debate might be played out. Uncovering alterations between draft and final versions, considering the style for documentation and the forms used to reinforce messages are all important means by which researchers might begin to critically engage with the policy-making process and 
outcomes. Policy as text is positioned, therefore, as attempts at explanation; the process is one of policy-explaining.

\section{Policy-framing}

Examining the ways in which policy-texts are attended to requires consideration of the wider forces marshalled in a policy's defence or attack. For if we conceive of policy mandate as permission then it is necessary to enquire about the wider Discourses that give succour to such position calls; we need to attend to the ways and means by which such explaining is framed. Here we find the necessity to consider the relationship between policy and Discourse.

Whilst much has been written on the matter, there is no agreement as to what is meant by policy as Discourse (Bacchi, 2000). What the field does provide for, however, are means by which we might consider the interplay between policy creation and response. In this regard policy as Discourse is intimately bound up with policy explaining; it seeks to explain the forces that seek to position the 'reader' and 'writer' of policy. Crucially, policy as Discourse shifts our understanding from policy-texts as accurate portrayers of intent to a realisation that the language used within the policy statements themselves actively construct the world to which they pertain. As noted:

...this perspective construes policy as a representation of the interplay between the policy text (the material embodiment of the policy document and associate forms), discursive practices involved in the production, distribution and consumption of policy, and wider social practices... (Adams, 2011: 60)

Understanding, then, is dependent upon economic, social and political ways of viewing the world. Such a view also locates Discourse as the provider of position calls; those possibilities to imbue texts and the reading thereof with meaning as a result of wider social, cultural and political potentialities. The problematisation process whereby discontent with the perceptions of the current situation is created leads to argumentation, that is, the forming of possible position calls: the framing of potential action and response: policy-framing. 


\section{Policy-forming}

But this is not enough. Whilst it is important that we identify the ways and means by which wider forces position potentialities for action, there is still a need to understand the ways in which action at the local level actively forms and reforms policy in the immediacy of the institution. To ignore this is to run the risk of the death of subject. In answer is the idea of policy-forming.

Before we attend to such a view, we need to consider, for a moment, agency. By accommodating the possibilities that action can occur outwith the intentions of policyexplaining and policy-framing, agentic action must be attended to. The frames offered through policy as Discourse could be viewed as the deployment of possibilities for action. Indeed, the way in which Discourse seeks to control and constrain by the very fact that its language forms that which of it speaks (Foucault, 1972) seems to proffer constrained possibilities: action as diminished and controlled. But we can counter this in three ways.

First, whilst the possibilities for action might be reduced, the act of choosing is not necessarily so constrained; it is the very act of choosing that so confers agency. Second, Discourses do not present secure knowledge systems; analysis does not seek to illuminate or repudiate truth, but rather highlight the preservation strategies that seek to maintain the status quo. It is the identification of the legitimation and/or subversion of socio-cultural, socio-economic and socio-political 'realities' that are of importance. Within the education profession we might be generous and say that maintenance is the result of a desire to continue good practice (we might be not so inclined however and state that such measures occur out of self-preservation strategies).

Third, we must be careful not to ascribe a positive correlation between thought and action, speech and act. And this is vital: we cannot assume static personae that exist concordant with internal thoughts beliefs and ideals. Whilst individuals may well have a certain level of internal consistency in their ideals and values and the ways these are expressed, such consistency is not immutable. Ways of acting cannot be solely down to internally held attitudes for this denies that individuals may well express different beliefs often at the same time. This does not deny attitude per se, but rather highlights that individuals will be swayed 
and persuaded, pulled and pushed by matters wider than their own personally held views. The ways in which individuals act and react within Discourse is not conveniently aligned with discourse.

It seems, then, that agentic action occurs within the explanations offered by policy explanations and the frames for response provided by Discourse. But it is this agentic action which requires further consideration. Here we need to examine the ways in which the position calls provided by text and Discourse are taken up, resisted or ameliorated. It is policy as position which provides for this (Adams, 2011). This perspective assumes that official sanctions are so oriented

not through the weight they carry as a result of political pronouncement but through actions at the level of individual discursive events. It assumes not only that the illocutionary force and perlocutionary effect of language and the relative positions adopted by individuals occur within the storyline of policy text but that agents therein themselves identify storylines which, in turn, reposition language and the individual/group. (Adams, 2011: 66)

It seems that such theorising offers much and I offer the 'position call' to encompass the interplay between the micro and macro; a means to explore how positioning theory can shed light on the way in which policy 'explaining' and policy 'framing' offer certain positions that can be taken up, resisted or altered by those in school. However, in doing so, I draw attention to the ways in which policy as local event is positioned rather than mediated, formed rather than interpreted. Essentially, conversation forms and reforms policy; '...the very discursive practices undertaken in an attempt to 'understand' policy mandate are the very acts which confer upon policy its tangible form' (Adams, 2011: 66). Thus is noted the realm of policy-forming.

\section{Examining policy}

Policy research, then, is not the simple attribution of cause and effect through the devouring of produced texts. The process of policy-forming, reading and reforming is more subtle than this. The above three categories of policy-explaining, policy-framing and policyforming highlight the different social-realms for policy. All offer position calls, that is to say, 
all proffer some touchstone upon which to alight in the drive to expound ideas, interpret and translate into action. These three realms offer a means whereby we might examine the interplay of and policy's interaction with, the social, cultural and political realms and are summarised in table 1.

Take table 1 here

With this in mind we are able to do three interrelated things. First, we might examine policy texts for the way in which they explicitly position certain problems. We are able to point to the position calls they provide and also shed light on the interpretation and reinterpretation that might occur. Second we might examine the ways in which such missives construct and are constructed by wider social, cultural and political forces. We are able to highlight the wider framing for policy through an appreciation of these wider position calls. Third, we might examine, through empirical processes the ways in which policy is positioned at the institutional level, that is, we might understand the forms given to policy through local discursive acts. Crucially, however, the adoption of the position call offers a mechanism whereby the researcher might examine policy as a continuous process of formation and reformation. The concept of 'the position call' permits the development of a series of snapshots that together construct a timeline of policy formation simultaneously at the level of the micro and macro and is represented in figure 2.

Take figure 2 here

\section{Conclusion}

What I have argued for here is a way of conceiving of policy that enables research to take place at a number of levels. Firstly, the way in which policy texts as efforts to explain are held up as necessary sources of information and sites for examination. But such texts are not simply created, rather they are part of, and in part form, the Discourse that permits or precludes certain positions from being offered. Attempts at both policy explanation and policy-framing offer position calls to the professional; specific contributions to the discursive act. But it is through discursive moments that policy is formed and reformed; policy as position comes to the fore and offers yet another site for the examination of the policy- 
process. What is considered here is the way in which producers and consumers are engaged in different practices, but nonetheless, that they wish to ensure common ground. Consensus, hopefully, prevails, built around shared values, expressed within Discourse. As Gee (2012: 23) notes, meanings 'are ultimately rooted in negotiation between different social practices with different interests by people who share or seek to share some common ground', for meaning is negotiated and contested socially. Whenever we speak we must make it clear who we are and what we are, in that context, indeed, the 'who' and the 'what' are context specific and in social institutions there is always the pressure to say and do the 'right' thing. But caution should prevail, for

there are limitations to research which aims to identify official and/or expert discourses in lay people's talk. Even though such work focuses upon subjectivity, it tends to use lay peoples' utterances simply to illustrate the availability of official and/or expert discourses. It fails to explore, and theorize how discursive constructions are used and by whom, in what combinations, within which contexts and with what consequences for subjectivity and experience. (Willig, 2000: 560)

But Gee goes on to say that on occasions one's performance does not get 'recognised' and thus does not 'count' with regard to the Discourse one is operating in at the time. In such cases one is either ignored or identified as marginal or 'Foreign' to the main Discourse. This implies a multiplicity of interpretation drawn from different readings of texts and Discourses. But attempts to deny this multiplicity and indeterminacy of interpretation often direct the work of institutions and elites, so that their own priviledged position might be maintained. In such instances, they take their own version of meaning to be 'natural, inevitable and incontestable' (Gee, 2012: 125). Schools, Gee (2012) says, should be about reflecting on and critiquing the wider Discourse maps of their society and the wider world, in order to enact and effect change. They should ensure that they stress the multiplicity and indeterminacy of Discourse and thus resist domination. As Willig writes 'in other words, our focus needs to shift from the availability of discursive resources in the culture to the individual's appropriation of (some of) these over time.' (2000: 560).

This sits in contradiction to the performative agenda so prevalent in current schooling structures. Furthermore, if we have ways of analysing and interpreting, then possibilities for 
action come to light; the heuristic device here presented offers such a mechanism. As a means by which we might inject theory into the analysis of social acts, the three realms of policy-explaining, policy-framing and policy-forming overlaid by the theory of the position call stemming from positioning theory give policy research a new heuristic device which explicitly acknowledges the multiplicity of Discourse and the discursive act. Through this mechanism exists a method for examining the ways in which Discourse, text and discourse give rise to a multitude of policy meanings formed at the local level.

\footnotetext{
When we look at individuals in their social contexts we should not let the context itself, the social discourse, interaction of culture be the active subject in our analysis. That easily happens when we take as our starting point of reference one single isolated context. When we look at social contexts in isolation they are in danger of losing their meaning for participants. Social contexts get their social meaning through their connection with other contexts, their connections with something more comprehensive. Furthermore, in a context the participants act on the basis of their participation in other contexts and what kind of meaning participation here has to them. (Hojholt, 1997: 1)
}

What this perspective adds is a new way of conceptualising how those matters that circulate above the immediate locale and those that permeate the immediacy of agentic action come together to provide a method for the examination of the what, how and where of policy. The heuristic device develops previous work undertaken by, for example, Ball and adds to it in three ways:

1. The position call is offered as a theoretical device which illuminates the way in which different locales stimulate policy formation

2. Positioning theory is used as a means to describe the relationship between the use of language, the positions adopted and given and the storylines implicit within the aforementioned locales.

3. Policy as positioning is offered as a means to understand the ways in which little-d discourse forms and reforms policy at the local level.

These three additions serve to develop policy-related educational research.

\section{References}


Adams, P. (2011) '(Dis)continuity and the coalition: primary pedagogy as craft and primary pedagogy as performance', Educational Review, 63(4), 467-483

Avis, J. (2006) 'Improvement through research: policy science or policy scholarship', Research in Post-Compulsory Education, 11(1), 107-114

Bacchi, C. (2000) Policy as discourse: What does it mean? Where does it get us? Discourse: Studies in the Cultural Politics of Education, 21(1), 45-57

Ball, S.J. (2006) Education Policy and Social Class: the selected works of Stephen J. Ball, London: Routledge.

Ball, S.J., Maguire, M. and Braun, A. (2012) How Schools Do Policy: policy enactments in secondary schools, Oxford: Routledge

Bamberg, M. (2004) "I know it may sound mean to say this, but we couldn't really care less about her anyway.' Form and functions of 'slut bashing' in male identity constructions in 15-year-olds', Human Development, 47(6), 331-353

Barnes, M. (2004) 'The use of positioning theory in studying student participation in collaborative learning activities', paper presented as part of the symposium 'Social Positioning Theory as an Analytical Tool', at the Annual Meeting of the Australian Association for Research in Education, Melbourne, November $28^{\text {th }}$ to December $2^{\text {nd }}$

Burr, V. (2003). Social Constructionism (2nd edn.), Hove: Routledge

Davies, B., \& Harré, R. (1999) 'Positioning and personhood', In Harré, R., \& van Langenhove, L. (Eds.) Positioning Theory, Oxford: Blackwell, 32-52

Department for Education (DfE) 2010 The importance of teaching: The schools white paper 2010, Norwich: The Stationery Office

Department for Education and Employment (DfEE) (1998) The National Literacy Strategy: Framework for teaching, London: DfEE.

Department for Education and Employment (DfEE) (1999) The National Numeracy Strategy, London: DfEE.

Dill, 1998) 'Evaluating the 'Evaluative State': implications for research in higher education', European Journal of Education, 33(3), 361-377

Drewery, W. (2005) 'Why we should watch what we say. Position calls, everyday speech and the production of relational subjectivity', Theory and Psychology 15(3), 305-24.

Fay, B. (1975) Social Theory and Political Practice, London: Allen and Unwin Foucault, M. (1972) The archaeology of knowledge, New York: Pantheon 
Gee, J.P. (2012) Social Linguistics and Literacies, Ideology in Discourses, London: Routledge

Grace, G. (1991) 'Welfare labourism versus the new right: the struggle in New Zealand's education policy', International Studies in Sociology of Education, 1(1-2)

Grace, G. (1995) School Leadership, Beyond Education Management. An Essay in Policy Scholarship, London: RoutldegeFalmer

Harré, R. (1997) 'Forward to Aristotle: The case for a hybrid ontology', Journal for the theory of social behaviour, 27, 173-191

Harre', R. (2004) Positioning theory, [Retrieved May 16, 2006, from http://www.massey.ac. nz/_alock/virtual/positioning.doc]

Harre', R., \& van Langenhove, L. (1999) The Dynamics of Social Episodes. In R. Harre' \& L. van Langenhove (Eds.), Positioning theory, London: Blackwell, pp. 1-13

Harré, R., Moghaddam, F.M., Cairnie, T.P., Rothbart, D. and Sabat, S.R. (2009) 'Recent advances in positioning theory', Theory and Psychology, 19(1), 5-31

Hojholt, C. (1997) 'Child development trajectories in social practice', paper presented at the Berlin Conference of the International Society for Theoretical Psychology, Berlin, $27^{\text {th }}$ April to $2^{\text {nd }}$ May

Holland, D., Lachicotte Jr, W., Skinner, D and Cain, C. (2008) 'Positioned identities', in P. Murphy and K. Hall (Eds.) Learning and Practice, Agency and Identities, London: Sage

Jones, R.A. (1999) 'Direct perception and symbol forming in positioning', Journal for the Study of Social Behaviour, 29(1), 37-58

Korobov, N. and Bamberg, M. (2004) 'Positioning a 'mature' self in interactive practices: how adolescent males negotiate 'physical attraction' in group talk', British Journal of Developmental Psychology, 22(4), 471-492

Linehan, C. and McCarthy, J. (2000) 'Positioning in practice: understanding participation in the social world', Journal for the Theory of Social Behaviour, 30(4), 435-453

Neave, G. (1998) 'The evaluative state reconsidered', European Journal of Education, 33(3), 265-284

Ofreneo, M.A.P. and Montiel, C.J. (2010) 'Positioning theory as a discursive approach to understanding same-sex intimate violence', Asia Journal of Social Psychology, 13(4), 247-259 
Rogers, R. (2004) Interview with James Gee. In Companion Website to R. Rogers (Ed.) An Introduction to Critical Discourse Analysis in Education ( $2^{\text {nd }}$ edn), New York: Routledge, [http://cw.routledge.com/textbooks/9780415874298]

Slocum-Bradley, N. (2009) 'The positioning diamond: a trans-disciplinary framework for discourse analysis', Journal for the Study of Social Behaviour, 40(1) 79-107

Strauss, C. (2012) Making Sense of Public Opinion: American discourses about immigration and social programs, Cambridge: Cambridge University Press

Tan, S.L and Moghaddam, F.M. (1995) 'Reflexive positioning and culture', Journal for the Theory of Social Behaviour, 25(4), 387-400

Troyna, B. (1994) 'Reforms, research and being reflexive about being reflexive. In D. Halpin and B. Troyna (Eds.) Researching Education Policy, Ethical and Methodological Issues, London: RoutledgeFalmer.

Van Langenhove, L. and Harre, R. (1999) 'Introducing positioning theory', in R. Harré and L. van Langenhove (Eds.) Positioning Theory: moral contexts of intentional action, Oxford: Blackwell Publishers Ltd

Willig, C. (2000) 'A discourse-dynamic approach to the study of subjectivity in health psychology', Theory and Psychology, 10(4), 547-570

Winslade, J. (2006) 'Mediation with a focus on discursive positioning', Conflict Resolution Quarterly, 23(4), 501-515 


\section{Position}
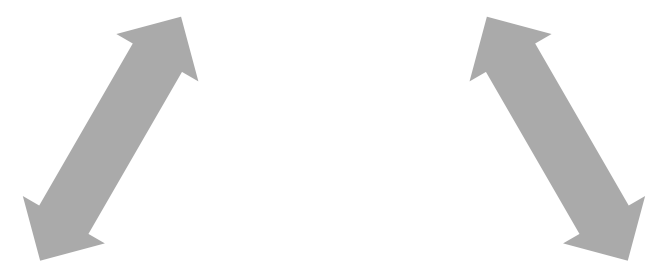

\section{Social force of language}

Storyline

Figure 1: The positioning triangle (Van Langenhove and Harré, 1999) 


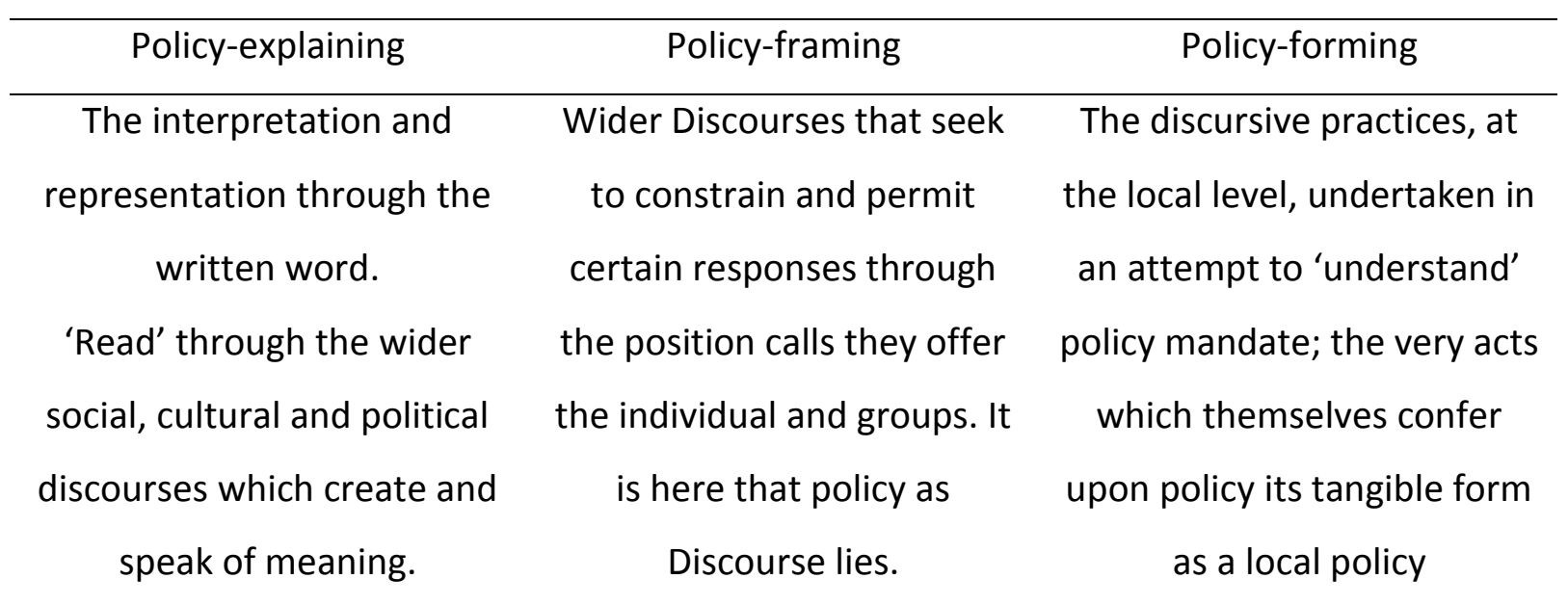

Table 1: the three realms for policy formation and analysis 


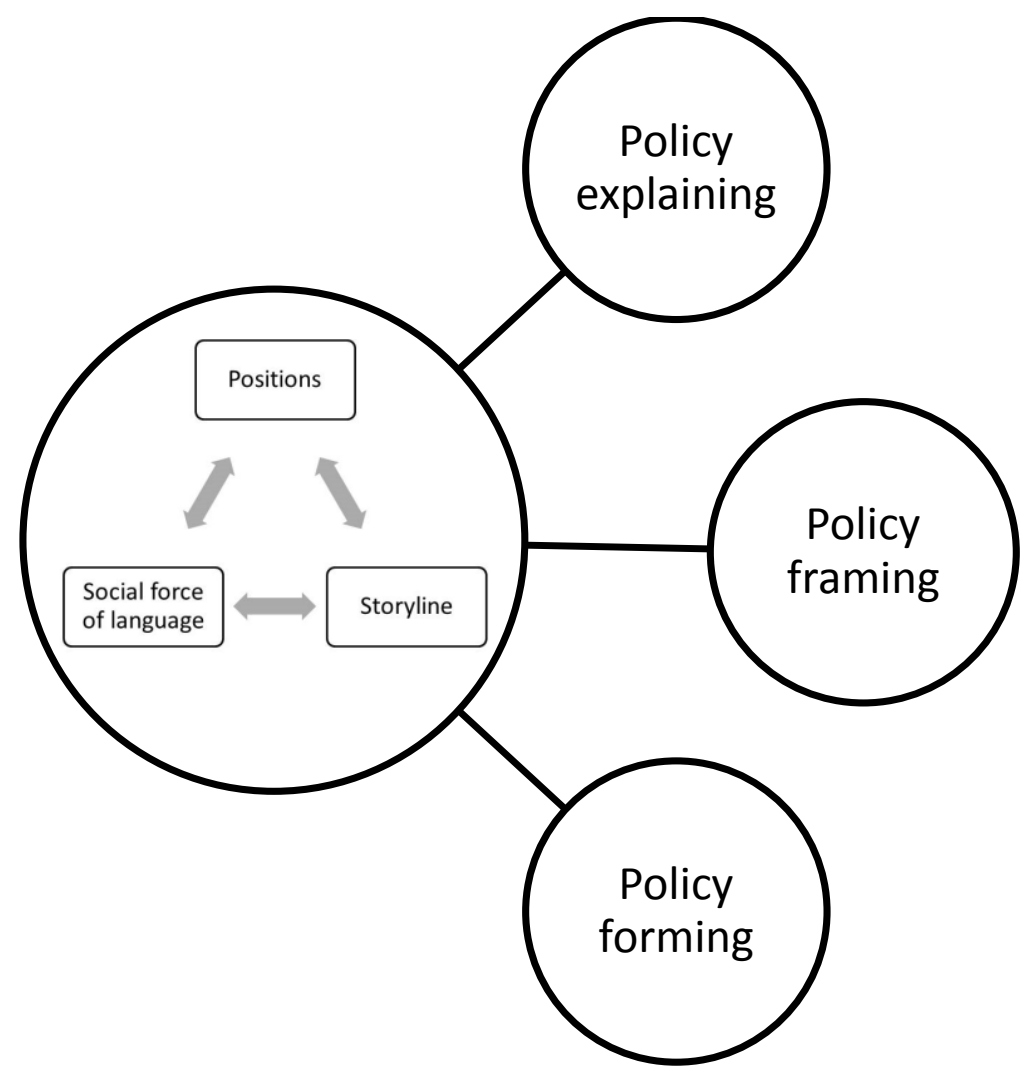

Figure 2: The policy research process 